\title{
Exploring rural futures together
}

\author{
M.E. WEDDERBURN ${ }^{1}$, T. T. KINGI ${ }^{2}$, A. D. MACKAY ${ }^{2}$, M. BROWN ${ }^{2}$, O. MONTES DE OCA ${ }^{2}$, K. MAANI $^{3}$, \\ R. BURTON ${ }^{4}$, H. CAMPBELL ${ }^{5}$, S. PEOPLES 6 , J. MANHIRE ${ }^{7}$, R. DYNES ${ }^{8}$, B. KAYE-BLAKE 9 \\ ${ }^{1}$ AgResearch Ruakura Research Centre, East Street, Private Bag 3123, Hamilton 3240 \\ ${ }^{2}$ AgResearch Grasslands, Private Bag 11008, Palmerston North \\ 3 School of Integrative Systems, The University of Queensland, Brisbane 4072, Australia \\ ${ }^{4}$ Centre for Rural Research, $N$-7491 Trondheim, Norway \\ ${ }_{5}^{5}$ Otago University, Dunedin \\ ${ }^{6}$ AgResearch, Invermay Research Centre, Private Bag 50034, Invermay \\ ${ }^{7}$ AgriBusiness Group Ltd, P.O Box 4354, Christchurch \\ ${ }^{8}$ AgResearch, Lincoln Research Centre, Private Bag 4749, Christchurch \\ ${ }^{9}$ NZIER, Wellington \\ Liz.Wedderburn@agresearch.co.nz
}

\begin{abstract}
The New Zealand pastoral industry has many simultaneous drivers, including market and policy compliance, that operate from the local to the global scale. The ability to adapt to these multiple drivers against a background of constrained natural resources and climate change is vital to the continued success of New Zealand's pastoral industry. Here we describe a case study based in the Horizons Region where we worked with pastoral sector stakeholders to apply a process in which an integrated systems perspective was used to identify and explore the impact of drivers on dairy and sheep/beef systems. Drawing from this process we have designed a generic framework, including tools and processes, to enable policy, farmers, and agribusiness to collectively explore the influence of multiple drivers on the future behaviour of farm systems and associated value chains.
\end{abstract}

Keywords: Rural futures, collective learning, socioecological systems, strategic planning

\section{Introduction}

Pastoral agriculture is a complex socio-ecological system that is reliant on the feedback between farmer behaviour, the farm's natural resources and its biological systems to generate a range of outputs necessary for human well-being (food, income, lifestyle etc.) and ecosystem integrity (water quality, soil integrity etc.). Farmers, although key decision makers, do not act in isolation but are embedded within a value chain system that integrates local to global scale pressures that drive behaviour. These many simultaneous pressures that include market (e.g. accreditation, product price, input costs, land values, skilled labour), societal (e.g. consumer perception) and policy factors (e.g. environmental regulation) (MAF 2007) also occur in a world of constrained natural resources, (Parliamentary Commissioner for the Environment 2004) offering both risks and opportunities for shaping industry growth. These drivers do not operate independently, but interact to produce complex and uncertain system behaviour both on- and off-farm, adding to the complexity of the challenges facing the sector and its multiple stakeholders. New means of enabling farmers' and other stakeholders' ability to explore, learn, plan, innovate and thus gain confidence to proactively and effectively respond to complexity are required if the pastoral industry is to continue to exist and thrive in the future. We have designed a research programme, "Rural Futures", to address these issues using an integrated and participatory approach requiring the application and development of system dynamics and systems thinking methodologies suited to dealing with complexity (Holling 2001). The vast majority of system dynamics research in agriculture is hard system modelling (Bawden 2007). In other words, most of the models represent some aspect of the biological faming system but have very little stakeholder input, nor do they extend into the social context of farming. The future of systems dynamics research in agriculture lies in the integration of biophysical and social elements, and we have incorporated this thinking into the Rural Futures programme. This paper reports some initial findings on the programme's progress in the application of system methods to enable the integrated and participatory exploration of future scenarios.

\section{Method}

The formalisation of a process for exploring futures through collective learning was undertaken in a case study based in the Horizons Region (ManawatuWhanganui) in a series of four workshops held between December 2009 and August 2010. The stakeholder group included: farm consultants, industry advisors, leading dairy and sheep/beef farmers, and individuals who represented the perspectives of MAF, Horizons 


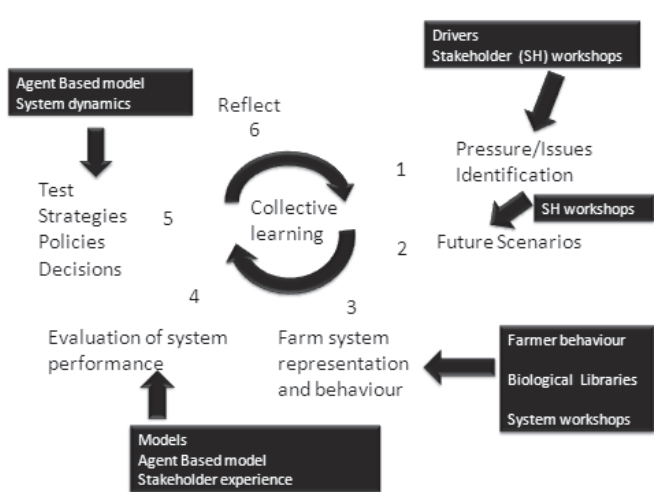

Figure 1 Framework for exploring futures through collective learning. Numbers $1-6$ refer to the steps in the text.

Regional Council, Federated Farmers and Maori Incorporations and Trusts.

Following a review of collective learning principles and system methodologies applied to complex systems (Maani \& Cavana 2007; Blackett 2009; Maani 2011), the following process and methods were chosen to apply to the case study. The purpose of Workshop 1 was to set the context for the stakeholder group. This was done by addressing the question, "what are the drivers and their relationships which influence New Zealand pastoral systems within the Horizons Region"? To gather a diversity of information quickly without processing it, affinity diagrams were used i.e. Post-it notes were used to capture one driver per person and then the drivers from the whole group were clustered under themes. In Workshop 2 the focus was on revealing the interconnections between the drivers and using a systems perspective to prioritise the drivers for study. The stakeholders constructed a Causal Loop Diagram (CLD) taking the themes identified in Workshop 1 and developing the relationships between them. In Workshop 3, the resulting conceptual diagram along with supplementary information presented on the drivers impacting on New Zealand pastoral farming in the next 10-15 years (Manhire 2009), was used by the stakeholders to choose drivers for the design and exploration of hypothetical 2020 future farms. These farms were constructed with the stakeholders, starting with base representative farm-models for both dairy and sheep/beef for the region in 2010. In Workshop 4 system performance was evaluated using live simulations of FARMAX ${ }^{\circledR}$ Pro, FARMAX ${ }^{\circledR}$ Dairy, and OVERSEER ${ }^{\circledR}$ nutrient budget model to allow immediate interaction and evaluation of questions related to the impact of the drivers on future farm systems. In all workshops the conversations were recorded and notes taken to ensure that the reasons for decisions made were captured.

\section{Results and Discussion}

We have designed a framework for exploring futures through collective learning (Fig. 1) based on the case study and the concept of a "learning lab" that integrates systems thinking, complex decision-making skills, and group learning (Maani \& Cavana 2007; Maani 2011). The framework has the collective learning cycle at its core with a focus on future agricultural systems and consists of six iterative steps.

\section{Step 1 Future drivers identification}

The range of drivers and their relationships identified through literature review (Manhire 2009) and stakeholder knowledge (Workshops 1 and 2) are captured and represented as a system using a CLD (Fig. 2). This demonstrates the link between drivers and the resulting integrated sub-systems of environmental policy, on farm response, economic signals, and family/ community. Farmer attitudes and values were noted as central to system performance. Developing the CLD stimulated discussion about the interconnectedness of the system and, in its construction, revealed the different world views of stakeholders as highlighted by the following insights from one stakeholder: "It was interesting, when you went back to the map to sort out what were the things that drive a business, to see that the loops captured most of the relationships. But I think it's when you take a driver and ask where you place it on the map, and what does it actually influence, that the process engendered some really interesting discussion". Not all stakeholders found the building of a CLD as part of driver identification intuitive, and

Table 1 Current and future (2020) attributes of dairy and sheep and beef base model farms in the Horizons Region. Figures in brackets indicate the predicted values in 2020.

\begin{tabular}{lll}
\hline Attribute & Dairy & Sheep and Beef \\
\hline Ownership & Owner operated & Owner operated \\
Effective area & 250 ha & $800 \mathrm{ha}$ \\
Fertiliser N kg/ha & $150(200)$ & $25(75)$ \\
Imported feed kg DM/cow & $450(2000)$ & \\
Stocking Rate & 2.8 cows/ha (3.16) & $10.3(11.4) \mathrm{SU} / \mathrm{ha}$ \\
Productivity & $\mathrm{kg} \mathrm{MS/cow} 950(1230)$ & Lambing $125 \%(138 \%)$ \\
& & Beef yearling 320kg (350) \\
\hline
\end{tabular}




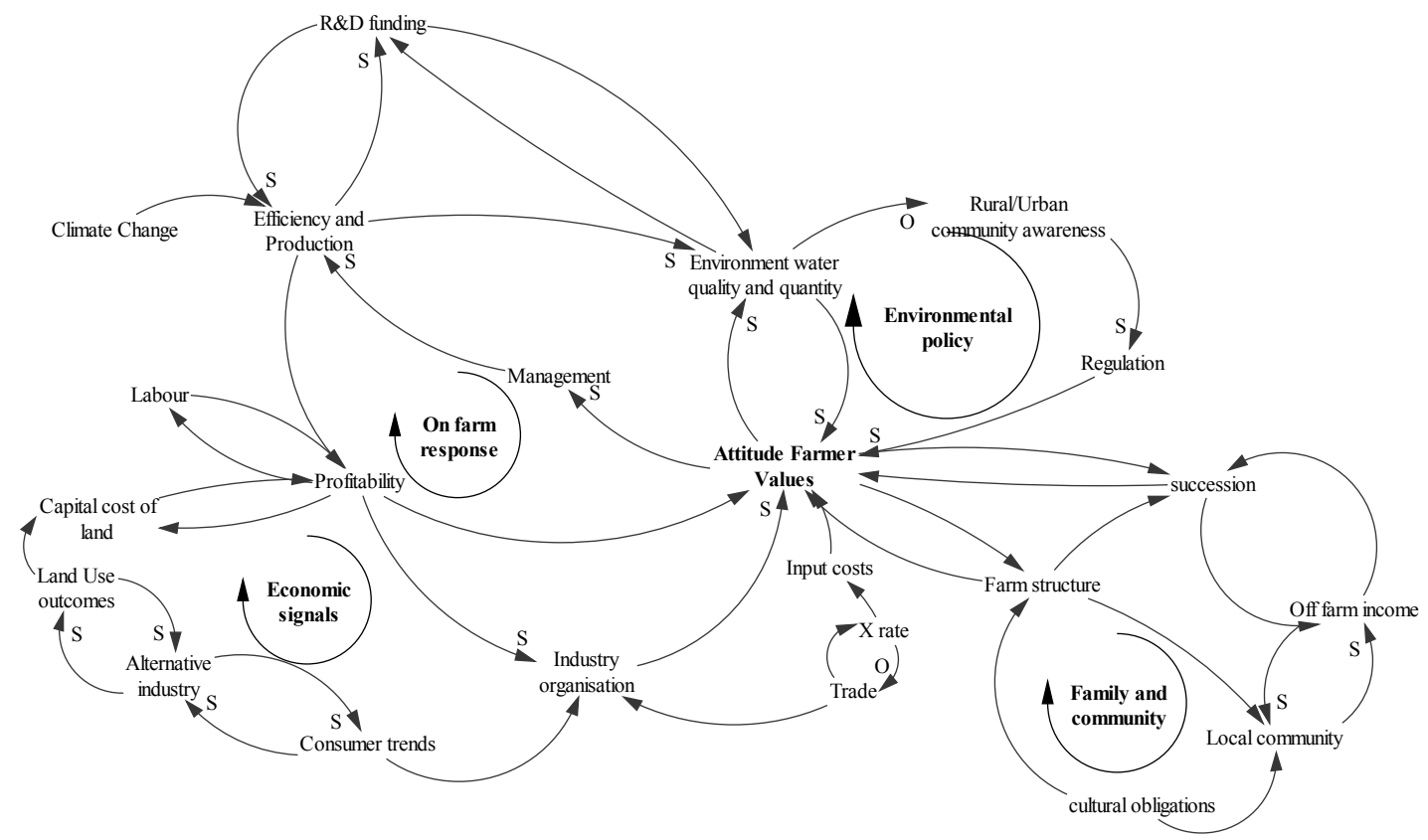

Figure 2 Causal Loop Diagram (CLD) of future drivers influencing New Zealand pastoral systems within the Horizons Region. S signifies drivers moving in the same direction, O signifies movement in the opposite direction

indicated a preference for being given a set of preprepared drivers. This could be due to the fact that thinking in feedback loops requires practice and is not obvious to many novice users of systems tools. The strength of the CLD was in making the linkages between the drivers transparent, and in demonstrating where particular drivers had key leverage throughout the system. This would not have been achieved with a simple list of drivers, and other research has shown that decision makers often miss the dynamics of complex issues (Morecroft 1983; Senge1991; Sterman 1989; Maani \& Maharaj 2004). The CLD is a conceptual model that can be used as the basis for the development of interactive models that allow stakeholders to explore changes in system behaviour and the consequences across economic, environmental and social subsystems. This is the foundation for building new experiences and knowledge.

\section{Step 2 Future Scenarios}

The stakeholders used the CLD to identify five drivers influencing performance throughout pastoral systems in the Horizons region. These were productivity and profitability, labour and staff skills, regulation, environmental constraints/limits and continued well being (survivability). These drivers were used to guide the development of the 2020 farm systems.

\section{Step 3 System representation and behaviour}

The characteristics identified by the stakeholders prominent among dairy and sheep/beef farms within the Horizons Region in the 10 years to 2020 are noted in Table 1. This was informed by analysis that indicated that regional growth in dairying was faster by $2.5 \%$ than the North Island but less than New Zealand by $4.2 \%$. The hill country farm size and stocking rate had increased by $1 \%$ per annum and production per farm by $2 \%$, whereas finishing farm size had increased by $2 \%$, and production per farm by $4 \%$. Even although the group had a wide exposure to the diversity of drivers and their relationships, the focus remained on "the business we know" and an expansion of the current business-growth model rather than transformative future farm systems. The exception was discussion on a low-input lifestyle sheep and beef option. The lack of stretch might reflect the limitations of starting from a current base and projecting out. Perhaps there was also an insufficiently diverse group of stakeholders to encourage a breadth of thinking i.e. there were no stakeholders representing environment or urban values. Additional elements that would facilitate transformative and beyond-currentreality thinking, such as design thinking (Martin 2006) and idealised design (Ackoff 1999), will have to be explored to stretch the view of the stakeholders. 


\section{Step 4 Evaluation of system performance}

The 2020 future farm systems performances were evaluated using FARMAX ${ }^{\circledR}$ Pro, FARMAX ${ }^{\circledR}$ Dairy and OVERSEER $®$ nutrient budget model. Discussion from the group generated considerable debate about how well the base farm models would represent the "average" farmer in the region in 2020. Many of the farm parameters, e.g., stocking rate, milksolids per cow and per hectare, were not significantly pushed beyond the current top performing farms in the region. There was general agreement that it may be reasonable to expect that in 10 years' time the "average" farmer would continue down a business-as-usual pathway, shifting to a position that reflected the current top $10 \%$ of the industry.

\section{Step 5 Testing strategies, policies and decisions} Using live simulations of FARMAX ${ }^{\circledR}$ Pro and FARMAX ${ }^{\circledR}$ Dairy interactively with the stakeholders gave them the opportunity to gain instant feedback on the consequences of farmer decisions on farm productivity and effective farm surplus. A significant proportion of the exercise was taken up by debating the farm parameters. This is an important part of the process as the participants must be confident in the model's capacity to represent a realistic future farm system. Many of the outcomes were consistent with the users' expectations; others generated debate e.g., how a farm might respond to labour shortage and automation.

FARMAX ${ }^{\circledR}$ Pro, FARMAX ${ }^{\circledR}$ Dairy and OVERSEER ${ }^{\circledR}$ nutrient budget model are credible tools to demonstrate farmer decisions on hypothetical farming systems, and outputs promoted wide discussion within the end user group. The case study as a test of the framework shows that it can be used to explore multiple simultaneous drivers on farm systems behaviour by utilising the modelling platform that underpins existing tools. This demonstrates the importance of the role that the next generation of tools will have in building stakeholder understanding of the emergent properties, behaviours and unintended consequences of farm systems experiencing multiple drivers required in Steps 4 and 5 of the framework. To facilitate this interactive learning, the Rural Futures programme is developing libraries for different farm type biological responses to enable an exploration of farm scenarios in Step 3 and inform the Multi-Agent Simulation model (MAS) in Steps 4 and 5. The MAS model of farmer decisionmaking behaviour uses the life cycle of farmers to develop risk profiles around decisions associated with land use change, and their practice is linked to farm biological response. The vision is that stakeholder groups will be able to participate in "live" interactions with the model to ask "what if" questions and to observe the implications of their strategies and policies before they are implemented. This enables experiential learning to adapt to uncertain and complex futures.

\section{Step 6 Reflect}

Building reflection time into the framework is important to allow the stakeholder group to pause and consider the repercussions of their activities. In reality, reflection occurred throughout the four workshops.

\section{Conclusion}

Our framework is designed for people who wish to explore the impact of long-term projections and to test adaptive strategies for uncertain and complex futures. Participating will assist in expanding perceptions and the knowledge needed in strategic planning. Anchored through context and place, the framework allows the exploration of multiple drivers simultaneously and integrates human behaviour with biological systems.

\section{ACKNOWLEDGEMENTS}

This work was funded by the Foundation of Research Science and Technology through the Rural Futures programme, with support from the following: Beef and Lamb, Dairy NZ, Environment Canterbury, Environment Waikato, Fonterra, Horizons Regional Council, Landcorp, MAF.

\section{REFERENCES}

Ackoff, R.L. 1999. Re-creating the corporation: a design of organizations for the 21st Century. Oxford University Press, Oxford.

Bawden, R. 2007 Redesigning animal agriculture. A systemic perspective. pp. 1-17 In: Redesigning animal agriculture: the challenge of the 21st century. Eds Swain, D.L.; Charmley, E.; Steel, J.; Coffey, S. CAB International, Wallingford.

Blackett, P. 2009. Stakeholder participation in system dynamics. AgResearch Internal Report.

Holling, C.S. 2001. Understanding the complexity of economic, ecological and social systems. Ecosystems 4: $390-405$

Maani, K. 2011. Learning lab for sustainability theory and case study (UNESCO Biosphere Reserves) Systems Dynamics Conference, Washington (July).

Maani, K.; Cavana, R. 2007. Systems thinking, system dynamics - managing change and complexity. Second Edition. Prentice Hall, Pearson Education. $278 \mathrm{pp}$.

Maani, K.; Maharaj V. 2004. Links between systems thinking and complex decision making. System Dynamics Review 20: 21-48.

MAF Future Focus, 2007. http://www.maf.govt.nz/ mafnet/publications/future-focus/ 
Manhire, J. 2009. New Zealand pastoral production: a review of issues, drivers, shocks and wildcards for the next 10-15 years. Internal Report, Agribusiness Unit, Lincoln University.

Martin, R. 2006. Design thinking and how it will change management education. Academy of Management Learning \& Education 5: 512-523.

Morecroft, J. 1983. System dynamics: portraying bounded rationality. OMEGA 11(2): 131-142.

Parliamentary Commissioner for the Environment. 2004. Growing for good: Intensive farming, sustainability and New Zealand's environment. Parliamentary Commissioner for the Environment. Accessed 31/8/11 http://www.pce.parliament.nz/ assets/Uploads/Growing-for-Good.pdf

Senge, P. 1991. The fifth discipline - the art \& practice of the learning organization. Random House, Adelaide.

Sterman, J. 1989. Modeling managerial behavior: misperceptions of feedback in a dynamic decision making experiment. Management Science 35: 321-339. 
